\title{
The inactive $X$ chromosome adopts a unique three-dimensional conformation that is dependent on Xist RNA
}

\author{
Erik Splinter, ${ }^{1}$ Elzo de Wit, ${ }^{1}$ Elphège P. Nora, ${ }^{2,3,4}$ Petra Klous, ${ }^{1}$ Harmen J.G. van de Werken, ${ }^{1}$ Yun Zhu, ${ }^{1}$ \\ Lucas J.T. Kaaij, ${ }^{1}$ Wilfred van IJcken, ${ }^{5}$ Joost Gribnau, ${ }^{6}$ Edith Heard, ${ }^{2}$ and Wouter de Laat ${ }^{1,7}$ \\ ${ }^{1}$ Hubrecht Institute-KNAW, University Medical Center Utrecht, Utrecht 3584 CT, The Netherlands; ${ }^{2}$ Mammalian \\ Developmental Epigenetics Group, Institut Curie, Paris F-75248, France; ${ }^{3}$ CNRS, UMR3215, Paris F-75248, France; ${ }^{4}$ INSERM, \\ U934, Paris F-75248, France; ${ }^{5}$ Erasmus Center of Biomics, Erasmus Medical Center, Rotterdam 3015 GE, The Netherlands; \\ ${ }^{6}$ Department of Reproduction and Development, Erasmus Medical Center, Rotterdam 3015 GE, The Netherlands
}

\begin{abstract}
Three-dimensional topology of DNA in the cell nucleus provides a level of transcription regulation beyond the sequence of the linear DNA. To study the relationship between the transcriptional activity and the spatial environment of a gene, we used allele-specific chromosome conformation capture-on-chip (4C) technology to produce high-resolution topology maps of the active and inactive $X$ chromosomes in female cells. We found that loci on the active $X$ form multiple long-range interactions, with spatial segregation of active and inactive chromatin. On the inactive $X$, silenced loci lack preferred interactions, suggesting a unique random organization inside the inactive territory. However, escapees, among which is Xist, are engaged in long-range contacts with each other, enabling identification of novel escapees. Deletion of Xist results in partial refolding of the inactive $X$ into a conformation resembling the active $X$ without affecting gene silencing or DNA methylation. Our data point to a role for Xist RNA in shaping the conformation of the inactive $X$ chromosome at least partially independent of transcription.
\end{abstract}

[Keywords: nuclear organization; 4C technology; X-chromosome inactivation; gene regulation; transcription]

Supplemental material is available for this article.

Received April 1, 2011; revised version accepted May 25, 2011.

The spatial organization of DNA in the cell nucleus is nonrandom and provides opportunities to facilitate DNA metabolic processes like transcription and replication. Each chromosome in a mammalian nucleus occupies a distinct spatial territory in the nuclear space, with the larger and gene-poor chromosomes adopting a more peripheral location, and smaller, gene-rich chromosomes adopting a more internal position inside the nucleus (Croft et al. 1999; Bolzer et al. 2005). Individual chromosomal segments also have preferred genomic neighbors in nuclear space, resulting in the spatial segregation of active from inactive chromatin and setting up the threedimensional (3D) structure of chromosomes (Simonis et al. 2006; Lieberman-Aiden et al. 2009). It has been argued that the nuclear positioning of genomic regions follows probabilistic rules and will therefore differ from cell to cell. It is dependent on not only the properties of the region itself, but also the characteristics of proximal

${ }^{7}$ Corresponding author.

E-mail w.laat@hubrecht.eu.

Article published online ahead of print. Article and publication date are online at http://www.genesdev.org/cgi/doi/10.1101/gad.633311. regions on the linear chromosome template (Misteli 2001; de Laat and Grosveld 2007). Although factors have been identified that are involved in organizing and maintaining loops between enhancers and genes (Drissen et al. 2004; Kagey et al. 2010), little is known about factors involved in higher-order chromosome folding. The fact that active genes come together in nuclear space strongly suggests that transcription shapes the $3 \mathrm{D}$ organization of the genome (Osborne et al. 2004; Schoenfelder et al. 2009; Papantonis et al. 2010). However, transcription inhibition studies often fail to produce significant conformational changes (Tumbar et al. 1999; Palstra et al. 2008; Muller et al. 2010). Aside from transcriptional activity, spatially segregated active and inactive chromatin domains differ in epigenetic marks (such as DNA methylation) as well as in bound trans-acting proteins. Because all of these factors may impact on chromosome topology and vice versa, separating cause and effect remains challenging.

Monoallelically expressed gene loci provide a useful model system to study the relationship between genome topology, transcriptional activity, and chromatin modifications. They are identical in DNA sequence, coexist in the same cell, and experience the same trans-acting 
environment, yet their chromatin composition, bound transcription factors, and expression status are completely different. Provided one can distinguish the two alleles, monoallelically expressed genes offer a unique opportunity to assess the impact of transcriptional activity and chromatin composition on nuclear and chromosomal organization. One of the most extreme and particularly intriguing examples of monoallelic gene expression is found on the mammalian female $\mathrm{X}$ chromosomes. In mammalian cells, one $\mathrm{X}$ chromosome is inactivated to achieve dosage compensation between male and female cells. Random X-chromosome inactivation (XCI) takes place during early embryonic development and is initiated by up-regulation of the Xist gene on the future inactive $\mathrm{X}$ chromosome $\left(\mathrm{X}_{\mathrm{i}}\right)$ (for review, see Senner and Brockdorff 2009; Barakat and Gribnau 2010). Xist encodes an untranslated RNA, and its accumulation on the $\mathrm{X}$ chromosome in cis creates a silent nuclear compartment that excludes RNA polymerase II and associated transcription factors (Chaumeil et al. 2006). Upon accumulation of Xist RNA, various proteins involved in silencing are recruited to the $\mathrm{X}$ chromosome, including Polycomb group (PcG) protein complexes PRC2 and PRC1. Along with this recruitment, a change in chromatin features is observed, with depletion of histone modifications linked with gene activity such as acetylation of H3K9 (H3K9ac) and an increase of heterochromatin marks such as trimethylation of $\mathrm{H} 3 \mathrm{~K} 27$ (H3K27me3) and methylation of H4K20 (H4K20me1). Subsequently, the $\mathrm{X}_{\mathrm{i}}$ becomes latereplicating and incorporates histone variants such as macro-H2A, and promoter sequences undergo CpG methylation, the final outcome of which is that most genes on the $\mathrm{X}_{\mathrm{i}}$ are stably silenced. Interestingly, some genes can escape from inactivation (Disteche 1995; Yang et al. 2010). Conditional deletion of Xist shows that, once established, Xist RNA no longer seems to be required to maintain XCI (Csankovszki et al. 1999; Wutz and Jaenisch 2000). Intriguingly, after establishment of XCI, loss of Xist does compromise PRC2 recruitment and macro-H2A incorporation, but silenced genes remain inactive (Csankovszki et al. 1999; Kohlmaier et al. 2004; Zhang et al. 2007; Pullirsch et al. 2010), presumably because epigenetic marks such as CpG methylation remain. A possibility not yet explored is that the $3 \mathrm{D}$ organization of the inactive $\mathrm{X}$ chromosome is important for maintenance of gene silencing. Indeed, although Xist RNA appears to result in spatial reorganization of the inactive $\mathrm{X}$ chromosome as seen under the microscope, it is not clear whether this is relevant for the initiation or maintenance of the inactive state.

The topology of the $\mathrm{X}$ chromosome and its position in the nucleus may well play a role in its expression status in various dosage compensation strategies. For example, in Drosophila, dosage compensation is achieved by upregulating the male $\mathrm{X}$ chromosome via the dosage compensation complex (DCC). This up-regulation is accompanied by male-specific folding of the $\mathrm{X}$ chromosome, which is dictated by the clustering of high-affinity binding sites (HAS) for the DCC (Grimaud and Becker 2009). Such a folding pattern was suggested to promote an efficient distribution of the DCC on the male X chromosome. Similarly, chromosome topology might be important in contributing to the spread of gene silencing via Xist RNA along the entire $\mathrm{X}$ chromosome in cis in mammalian cells. In the mouse, Xist is located on the acrocentric $\mathrm{X}$ chromosome $\sim 100 \mathrm{Mb}$ away from the centromere and $\sim 65 \mathrm{Mb}$ away from its telomere. Nothing is known about how Xist RNA spreads or coats the X chromosome. It may proceed linearly along the chromatin fiber and/or diffuse to X-linked regions that are in spatial proximity to the site of Xist RNA production. The latter can be expected to greatly enhance the efficiency of this process at both the initiation and maintenance phases of XCI.

Most of our current knowledge of mammalian X-chromosome folding is based on fluorescence in situ hybridization (FISH) studies interrogating the position of genes in relation to the chromosomal territory (Dietzel et al. 1999; Chaumeil et al. 2006; Clemson et al. 2006). It was found that the core of the Xist territory is composed mainly of repetitive sequences, while genic sequences reside more on the edge of the territory. During XCI, genes that are inactivated are relocated from the edge to occupy a more internal position, while escapees remain looped out or at the outer edge of the Xist domain, in contact with the transcription machinery (Chaumeil et al. 2006). Xist was found to be crucial for this relocalization, as Xist RNA lacking the critical repeat A region did accumulate on the $\mathrm{X}$ in cis but was unable to induce gene silencing (Wutz et al. 2002) or gene relocalization (Chaumeil et al. 2006).

Although microscopy-based studies have been informative to study $3 \mathrm{D}$ genome organization, more recently developed techniques based on chromosome conformation capture (3C) (Dekker et al. 2002) have enabled a much more detailed and comprehensive view of chromatin folding and chromosome organization in the nucleus. While 3C analyzes interactions between single, selected DNA fragments (one versus one), adapted versions of $3 \mathrm{C}$ allow for increased throughput analyses, with chromosome conformation capture-on-chip (4C) analyzing interactions between one versus all (Simonis et al. 2006), chromosome conformation capture carbon copy (5C) analyzing many versus many interactions (Dostie et al. 2006), and HiC analyzing all versus all (Lieberman-Aiden et al. 2009; Rodley et al. 2009; Duan et al. 2010). All C methods are based on fixing the $3 \mathrm{D}$ genome inside living cells, digesting the DNA, and ligating the cross-linked fragments to each other. By quantifying ligation products, a measure of colocalization frequency can be obtained by either PCR, microarrays, or next-generation sequencing (NGS). $4 \mathrm{C}$ and $\mathrm{HiC}$ are the two methods for generating genome-wide interaction profiles. For a given throughput, HiC provides a low-resolution 3D map of all genomic interactions, while 4C gives a highly detailed interaction map for a single locus.

Here, we designed a strategy to allele-specifically direct 4C technology to active $\mathrm{X}$ chromosome $\left(\mathrm{X}_{\mathrm{a}}\right)$ - and $\mathrm{X}_{\mathrm{i}}$ associated gene loci in differentiated female mouse neural precursor cells (NPCs) to gain detailed insight into the folding of the X chromosome in its euchromatic or heterochromatic state. We provide the first high-resolution interaction maps of the active and inactive $\mathrm{X}$ chromosomes 
and demonstrate that the $\mathrm{X}_{\mathrm{a}}$ and $\mathrm{X}_{\mathrm{i}}$ fold very differently, with inactive loci on the $X_{i}$ being unique in having lost their preference to colocalize with a defined subset of other chromosomal loci. This random organization of inactive genes within the inactive X-chromosome territory is in sharp contrast to the more defined positions of escapees, which we found preferentially colocalizing and at the periphery of the $\mathrm{X}_{\mathrm{i}}$ domain. In fact, the $4 \mathrm{C}$ interaction profiles of escapees allowed novel escape genes to be identified in the cell type studied. By deleting the Xist locus in the same cells, we demonstrate that Xist depletion results in partial refolding of the $X_{i}$ to a structure that looks more reminiscent of the $\mathrm{X}_{\mathrm{a}}{ }^{\prime} \mathrm{s}$ conformation. This change in chromosomal organization is not accompanied by overt changes in transcriptional activity or DNA methylation on the $\mathrm{X}_{\mathrm{i}}$. Our data demonstrate how a long noncoding RNA impacts on chromosome folding in a manner that is at least partially independent of transcription and DNA methylation.

\section{Results}

Allele-specific 4C analysis discriminates between the active and inactive $X$ chromosome in NPCs

We applied 4C technology to enable a detailed study of the conformational differences between the active and inactive $\mathrm{X}$ chromosome in female cells. 4C technology allows for screening the genome in an unbiased manner for DNA regions that interact in the nuclear space with a locus of choice. Based on validation of interaction frequencies of $>100$ pairs of loci, both within and between chromosomes, by high-resolution cryo-FISH (Simonis et al. 2006; Palstra et al. 2008; data not shown), we demonstrated previously that this strategy robustly identifies contacting chromosomal regions. To direct the analysis specifically to either the active or inactive $\mathrm{X}$ chromosome, we used clonal F1 cell lines that had inactivated either the Mus musculus (SVJ129) or the Mus musculus castaneus (CAST) X chromosome (see below). Single-nucleotide polymorphisms (SNPs) creating allele-specific restriction sites were used for the exclusive degradation of the 4C template of one of the alleles, thereby enabling amplification and analysis only of the other allele (Fig. 1A,B; Supplemental Fig. S1A-C; further details in the Materials and Methods). Dedicated microarrays (Simonis et al. 2006) as well as NGS were used in combination with $4 \mathrm{C}$ for the analysis of DNA interactions (see the Materials and Methods). The two strategies yielded highly similar results (Supplemental Fig. S1D,E), but 4C in combination with NGS, or 4C-seq, offers several advantages, the most important being the higher putative coverage and, theoretically, an unlimited dynamic range, providing increased sensitivity and better resolution. Thus, 4C-seq provides highly detailed interaction maps for selected genomic loci.

In vitro differentiation of female embryonic stem cells (ESCs) is accompanied by the random inactivation of one the $\mathrm{X}$ chromosomes in a process that recapitulates the molecular events of in vivo $\mathrm{X}$ inactivation (for review, see

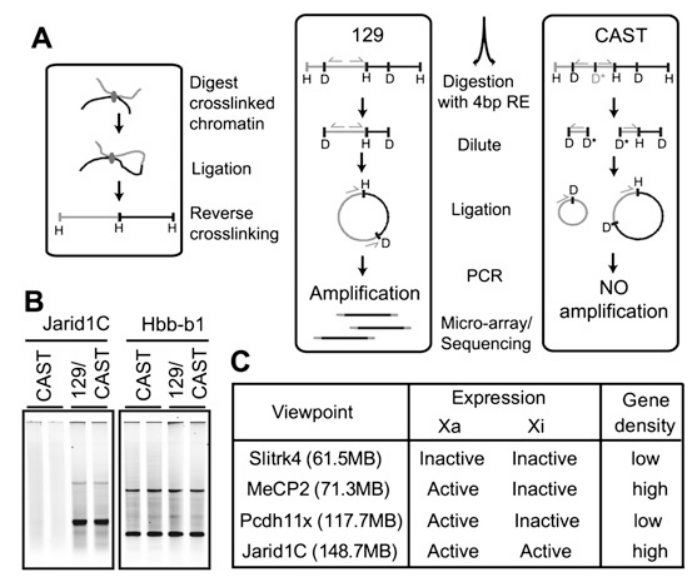

Figure 1. Outline of the allele-specific 4C approach to interrogate X-chromosome folding. (A) Schematic outline of the allele-specific 4C approach. Restriction fragment length polymorphisms (RFLPs) were identified and used to direct the 4C analysis to either the 129SVJ or the CAST allele. (B) 4C PCR products using allele-specific primers (Jarid1C, 129SVJ-specific) and primers not designed around a RFLP $(H b b-b 1)$ separated on an agarose gel. $(C)$ Four genes with different characteristics, representing different genomic environments, were chosen as viewpoints for the 4C analysis. An alternative allele-specific 4C approach and details concerning the use of NGS to analyze the 4C data can be found in Supplemental Figure S1.

Barakat and Gribnau 2010). XCI is completed at the stage when 7-d-old embryoid bodies (EBs) are formed. As EBs contain mixtures of cells from all germ layers and $4 \mathrm{C}$ (and other 3C-based methods) provides an approximation of the average chromatin structure present in all cells analyzed, we continued differentiation until NPCs were obtained (Supplemental Fig. S2A). NPCs show clear Xist RNA domains (Supplemental Fig. S2B) that are highly enriched in H3K27me3 (Supplemental Fig. S2C). Moreover, DNA methylation of promoters was observed on $\sim 50 \%$ of the X-linked alleles analyzed (Supplemental Fig. S2D). Together, this is indicative of complete XCI. XCI is random, but, once established, it is stably propagated to daughter cells. We confirmed this by selecting NPC clones from single cells, which exclusively inactivated either their $\mathrm{X}^{129}$ or the $\mathrm{X}^{\mathrm{CAST}}$ chromosome (Supplemental Fig. S2E). Using these NPC clones, we were thus able to direct $4 \mathrm{C}$ analysis specifically to the active or inactive $\mathrm{X}$ chromosome.

\section{Shared long-range interactions between active genes and between inactive genes present on the active $X$ chromosome}

To understand conformational changes imposed on the $\mathrm{X}$ chromosome by the noncoding RNA Xist, we first analyzed the active $\mathrm{X}$ chromosome. Four genomic loci, or "viewpoints," were initially chosen because they are embedded in different prototypical chromosomal contexts with respect to gene activity, gene density, or their ability to escape XCI (Fig. 1C). We started by investigating the nuclear environment of two active $\mathrm{X}$-linked genes $(\mathrm{MeCP} 2$ and Jarid1C), which are located in different gene-dense regions of the $\mathrm{X}$ chromosome. Both genes were engaged in 
many DNA interactions in cis across the entire $\mathrm{X}$ chromosome (Fig. 2A), as well as in trans (Fig. 2B). Each gene was also found to contact the other gene, despite being separated almost $80 \mathrm{Mb}$ on the linear DNA template. In

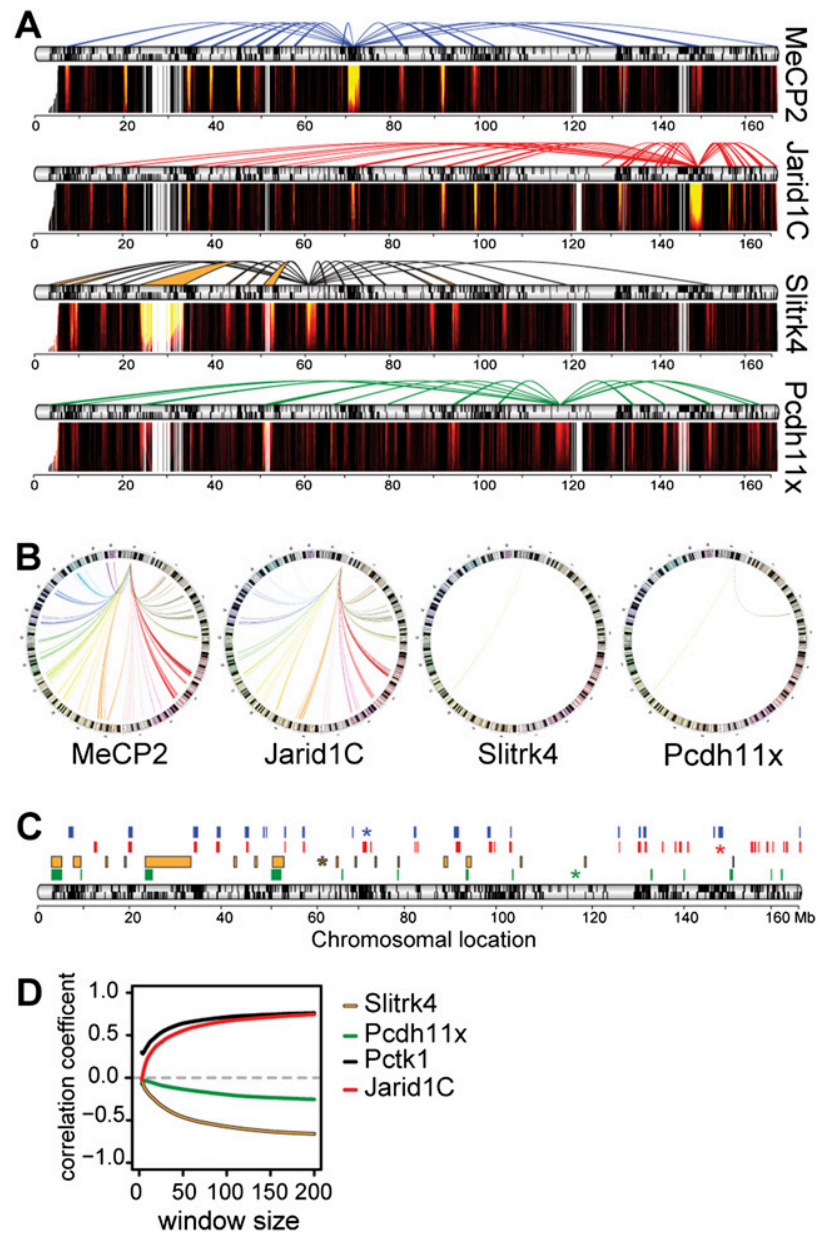

Figure 2. Long-range interactions engaged by the different viewpoints separate active from inactive chromatin on the active X chromosome. (A) Spider plots combined with domainograms depict long-range interactions identified with the four different viewpoints on the active X chromosome. Significant interactions are depicted in the spider plot by the different colored lines, each color representing a different viewpoint. Small black bars below the spider plot represent genes located on the X chromosome. Significance of interaction is indicated by the range in color used in the domainogram below each spider plot; black is low significance $(P=1)$ and yellow represents high significance $\left(P=10^{-10}\right)$ of interaction. $(B)$ Interactions with other chromosomes are depicted in Circos plots; each line represents a trans interaction. Chromosomes are plotted around the circle. Colors indicate the chromosomes that were contacted. $(C)$ Cis interactions from $A$ merged into one figure for comparison. Interactions are represented by the colored bars $(M e C P 2$, blue; Jarid1C, red; Slitrk4, gold; and Pcdh11x, green). The colored asterisk indicates the position of each viewpoint on the $\mathrm{X}$ chromosome. (D) Spearman's correlation calculated comparing 4C profiles of $P \operatorname{ctk} 1^{\mathrm{Xa}}, \operatorname{Slitrk} 4^{\mathrm{Xa}}, P \operatorname{cdh} 11 \mathrm{x}{ }^{\mathrm{Xa}}$, and $\operatorname{Tarid1} C^{\mathrm{Xa}}$ to $M e C P 2^{\mathrm{Xa}}$. Further characterization of the identified interacting regions can be found in Supplemental Figure S3. fact, the two genes shared many of their interacting regions in cis as well as in trans (Fig. 2C; Supplemental Table S1). Characterization of the cis-interacting regions revealed that they were, on average, $490 \mathrm{~kb}$ in size and enriched for other active genes that also locate in gene-dense regions of the X (Supplemental Fig. S3A,B). Furthermore, contacted regions show an enrichment of SINE repeats and a depletion of LINE repeats, which is typical for gene-dense regions (Supplemental Fig. S3C). Regions that were located on other chromosomes, contacted by the two genes, showed similar characteristics (data not shown).

Two other genes analyzed-Pcdh11x and Slitrk4-were located in gene-poor regions, with $P c d h 11 x$ being active and Slitrk 4 being inactive in NPCs. Both were found to be engaged in many specific long-range interactions in cis (Fig. 2A), but formed few specific contacts with other chromosomes (Fig. 2B). In contrast to MeCP2 and Jarid1C, interactions with the inactive Slitrk4 were mostly with other inactive, gene-poor sequences on the X. Correspondingly, these regions were enriched in LINEs and depleted for SINEs. Surprisingly, Pcdh11x, which is thought to be an active gene (Mikkelsen et al. 2007), contacted regions with similar characteristics of inactivity and, in fact, shared many of its interacting partners with the inactive Slitrk4 gene (Fig. 2C). However, when analyzed by RNA FISH, Pcdh11 $x$ was found to be active in only $13 \%$ of cells, implying that this gene is, in fact, inactive in most cells analyzed at a given time by $4 \mathrm{C}$. For comparison, MeCP2 and Jarid1C loci were detected as active by RNA FISH in $>95 \%$ of the cells (data not shown). Collectively, the data show that, irrespective of its activity and chromosomal context, each gene is engaged in many specific long-range DNA interactions across its chromosome. Active genes far apart on the chromosome, located in gene-dense regions, interact with each other and share a distinct set of interactions with other active genes in cis and in trans. "Inactive" genes separated on the chromosome and located in gene-poor regions similarly share interactions, but now with other inactive regions. This spatial segregation of active from inactive chromatin is also illustrated by the anti-correlation found for $4 \mathrm{C}$ profiles of inactive genes versus active genes (Fig. 2C,D). The applied Spearman's rank correlation analysis values similarity between the interaction profiles of two experiments by comparing the calculated $Z$-scores (depicted in the domainograms). Active, gene-dense regions clearly show more interchromosomal DNA interactions than the more inactive gene-poor regions. This is in agreement with gene-dense active chromatin being more often looped out or at the periphery of the chromosome territory than inactive regions (Mahy et al. 2002a).

\section{Inactive genes are positioned randomly inside the territory of the inactive $X$ chromosome}

Having established an understanding of $\mathrm{X}_{\mathrm{a}}$ conformation of the active $\mathrm{X}$ in NPCs, we next focused on the inactive $\mathrm{X}$. First, we confirmed that the two genes analyzed above$M e C P 2$ and Pcdh11x-were indeed both subject to silencing on the $\mathrm{X}_{\mathrm{i}}$ in NPCs (Supplemental Fig. S2E; data not 
shown). To our surprise, $4 \mathrm{C}$ revealed that the two genes showed a near complete loss of specific long-range contacts on the $\mathrm{X}_{\mathrm{i}}$ (Fig. 3A). The same was found for Slitrk4, which is inactive on both $X_{i}$ and $X_{a}$ in NPCs. Whereas captured sequences on the $\mathrm{X}_{\mathrm{a}}$ tend to cluster at specific regions, indicative of the formation of specific contacts, the long-range captured sequences of all three silenced loci on the $\mathrm{X}_{\mathrm{i}}$ are distributed much more randomly. This was not due to limited restriction digestion efficiency, which was similar for active and inactive genes across the $X_{i}$ (data not shown). It was also not caused by an inability of the $\mathrm{X}_{\mathrm{i}^{-}}$ linked inactive genes to reach outside their local chromatin structure, as, compared with their counterpart genes on the $X_{a}$, they all capture a relatively higher number of sequences over large $(>1 \mathrm{Mb})$ versus short $(<1 \mathrm{Mb})$ distances in cis (Supplemental Fig. S4B). The random distribution of long-range captured sequences on the $\mathrm{X}_{\mathrm{i}}$ suggests that inactivated loci on the $X_{i}$ no longer reside in preferred 3D genomic neighborhoods. This loss of specific contacts has not been observed in previous $4 \mathrm{C}$ or HiC studies (Simonis et al. 2006; Lieberman-Aiden et al. 2009), and in this study was exclusive for inactive loci on the $\mathrm{X}_{\mathrm{i}}$, since inactive loci on the $\mathrm{X}_{\mathrm{a}}$ (Fig. 2A) as well as on autosomes (data not shown) did show normal interactions.

\section{Escaping genes cluster and locate to the periphery of the Xist domain}

Unlike silenced genes, Jarid1C, a gene well known to escape the XCI process, formed multiple long-range in-

A
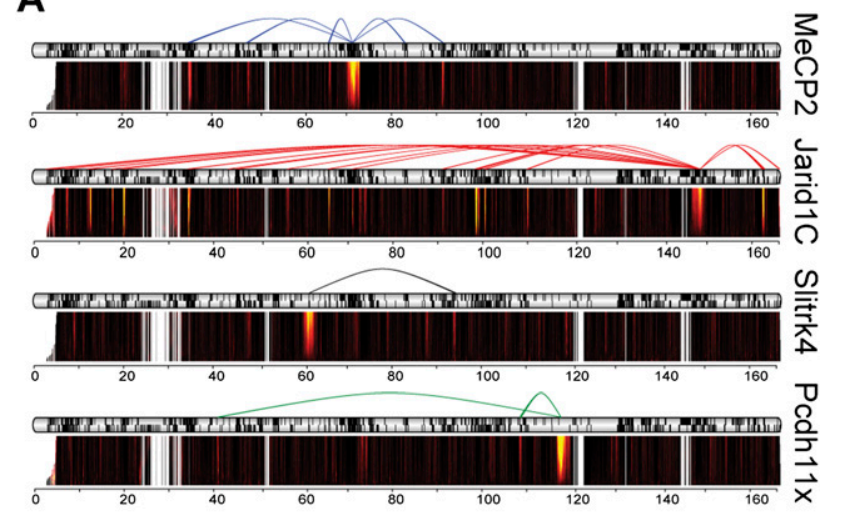

B

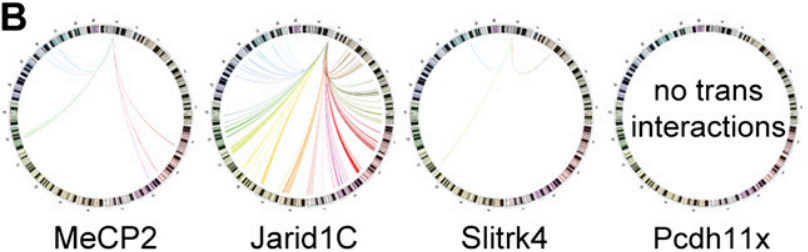

Figure 3. Allele-specific $4 \mathrm{C}$ analysis reveals dramatic changes in chromosome conformation on the inactive $\mathrm{X}$ chromosome. (A) Spider plots combined with domainograms depict long-range interactions identified on the inactive X chromosome. (B) Trans interactions of the different viewpoints are depicted in Circos plots; each line represents a trans interaction. Detailed analysis of the distribution of captured sequences on the $\mathrm{X}_{\mathrm{i}}$ can be found in Supplemental Figure S4. teractions on the $\mathrm{X}_{\mathrm{i}}$ (Fig. 3A). Moreover, Jarid1C and other escapees (see below) were the only genes on the $\mathrm{X}_{\mathrm{i}}$ to show many specific interactions with regions on other chromosomes. This is consistent with the previous observation of repositioning of silenced chromatin to a more internal position of the $X_{i}$ compared with escapees, which are positioned at the periphery or outside of the Xist RNA domain (Dietzel et al. 1999; Chaumeil et al. 2006). As active genes are known to be able to come together in nuclear space (Fig. 2A; Simonis et al. 2006; Lieberman-Aiden et al. 2009), we wondered whether contacts in cis were made with other genes escaping XCI. Indeed, the few genes known to escape XCI-such as Utx, Eif2s3x, Xist, and MidI, the latter located in the pseudoautosomal region-were located within regions contacted by Jarid1 $C^{\mathrm{Xi}}$ (Fig. 4A). This prompted us to investigate whether we could identify other escapees based on the 4C interaction profile of Jarid1C on the $\mathrm{X}_{\mathrm{i}}$. Employing a database of SNPs between 129/SvJ and CAST (Frazer et al. 2007), we tested eight other regions contacted by $\operatorname{Tarid} 1 C^{\mathrm{Xi}}$ for the presence of escapees by cDNA analysis (see the Materials and Methods for details). All of them contained at least one escapee, whereas all analyzed genes residing in noncontacted regions did not escape XCI (Fig. 4A; Supplemental Table S2).

One of the most distal contacts made by Jarid1C is with Pctk1, a gene located in a gene-dense area $\sim 128 \mathrm{Mb}$ away on the linear template. When analyzed, we found that Pctk1 also escapes XCI (Fig. 4A). We used this gene and Xist, well known for its activity on the $\mathrm{X}_{\mathrm{i}}$, as new viewpoints for further querying the structure of chromatin that escapes XCI. Like Jarid1C, Pctk1 and Xist are engaged in many long-range interactions across the entire inactive X chromosome. Most interactions were shared between the interrogated escaping genes (Fig. 4C), providing more evidence for the concept of escapees being capable of meeting each other in the nuclear space. Both Jarid1C and Pctk1 showed many interchromosomal interactions when analyzed from the $\mathrm{X}_{\mathrm{i}}$, even more than when analyzed from the $\mathrm{X}_{\mathrm{a}}$ chromosome (Fig. 3B; data not shown), confirming that these escapees preferentially locate at the periphery or outside of the nuclear territory occupied by the inactive X (Chaumeil et al. 2006; Clemson et al. 2006). RNA FISH experiments using probes against nascent transcripts have shown that most genes transcribe in bursts and are active only part of the time (Osborne et al. 2004; Chubb et al. 2006). This would suggest that interaction frequencies between discontinuously transcribed genes will be much higher when measured by nascent RNA FISH compared with DNA FISH, if such contacts are dependent on ongoing transcription. We found no obvious differences when interaction frequencies between pairs of genes on the inactive $\mathrm{X}$ were measured by RNA or DNA FISH, even for genes that are active $<65 \%$ of the time. This argues that the colocalization of escapee loci may not be dependent on ongoing transcription (Supplemental Fig. S5D,E). We further noticed that the regions contacted by Jarid1C and Pctk1 on the $\mathrm{X}_{\mathrm{i}}$ were not necessarily the same as those contacted on the $\mathrm{X}_{\mathrm{a}}$. In fact, Spearman's rank 


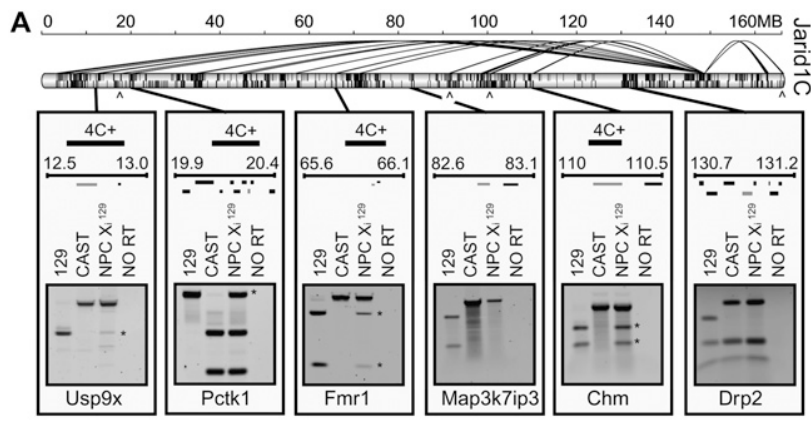

B

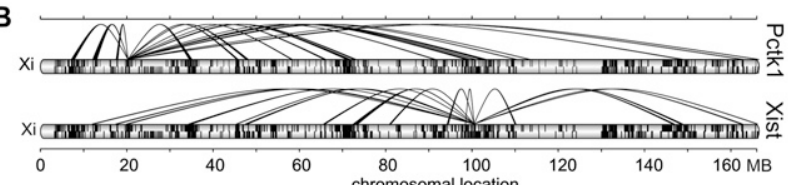

C

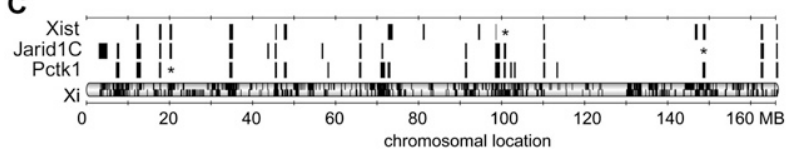

Figure 4. Escaping genes cluster in nuclear space. Jarid1C $\mathrm{C}_{-}^{\mathrm{Xi}}$ interacting regions contained other escapees. $(A)$ Genes known to escape XCI-(from left to right) Utx, Eif2s3x, Xist, and MidI-are indicated by arrowheads below the chromosome. The location and size of these regions are represented by the scaled black bars. The gel pictures show the result of the allelespecific cDNA analysis performed on the indicated genes (gray) located within the Jarid $1 \mathrm{C}^{\mathrm{Xi}}$-interacting regions. Other genes present in the interrogated region are drawn in black. The asterisk indicates the PCR product of transcripts originating from the $\mathrm{X}_{\mathrm{i}}$. Map3k7ip3 and Drp2 locate outside Jarid1C ${ }^{\mathrm{Xi}}$. interacting regions and were found silenced on $\mathrm{X}_{\mathrm{i}} .(B)$ Spider plot depicting long-range interactions of $\operatorname{Pctk}^{\mathrm{Xi}}($ top $)$ and Xist ${ }^{\mathrm{Xi}}$ (bottom). (C) Bars representing long-range cis interactions on the $\mathrm{X}_{\mathrm{i}}$ from Xist, Jarid1C, and Pctk1 are plotted for comparison. Asterisks indicate the position of the interrogated genes on the $\mathrm{X}$ chromosome. 3D FISH analysis confirming the interactions identified by 4C can be found in Supplemental Figure S5A-C.

correlation analysis comparing the $\mathrm{X}_{\mathrm{i}}$ and $\mathrm{X}_{\mathrm{a}}$ for the same locus (Supplemental Fig. S6) revealed that the cis interaction profiles of escapees were as dissimilar as those of the nonescaping genes. Collectively, these data argue for a unique topology of the inactive $\mathrm{X}$ in which randomly folded inactive chromatin makes up the core, while escapees are positioned at the periphery of the $\mathrm{X}_{\mathrm{i}}$ territory. The trans interaction profiles of escapees on the $\mathrm{X}_{\mathrm{a}}$ and $\mathrm{X}_{\mathrm{i}}$, on the other hand, showed a high percentage of overlap (Supplemental Table S1), arguing that the two X chromosomes in female cells do not adopt different positions relative to autosomes.

Deletion of Xist causes partial refolding of the inactive $X$ to a structure reminiscent of the active $X$ chromosome without affecting its inactive state

The $\mathrm{X}$ chromosome is particularly suited for studying factors that dictate chromosome shape, as its conformation completely changes upon the expression of the long noncoding Xist transcript. Xist is crucial for initiation, but is not required for maintenance of XCI. In order to assess whether Xist RNA dictates X chromosome conformation, even after the initiation phase of XCI, we used a similar conditional knockout strategy to ablate Xist in NPCs (Fig. 5A) as was published before (Csankovszki et al. 1999; Kohlmaier et al. 2004; Pullirsch et al. 2010). After inducing deletion of Xist and subsequent culturing of the Xist ${ }^{K O}$ NPCs for 2 wk (cell numbers increased $>10$ fold), analysis of DNA and RNA levels revealed that $\sim 80 \%$ of the cells harbored a recombined Xist locus (Fig. 5B,C; Supplemental Fig. S7A). As reported previously, the knockout of $X$ ist showed a dramatic reduction in Ezh2 and H3K27me3 accumulation on the inactive $\mathrm{X}$ (Fig. 5D,E). This occurred without changing DNA methylation levels on the $\mathrm{X}_{\mathrm{i}}$, or reactivating expression of silenced genes (Fig. 5F,G).

To determine the consequences of Xist depletion on the $3 \mathrm{D}$ structure of the $\mathrm{X}$ chromosome, we performed allelespecific 4C, as before, on Xist ${ }^{K O}$ and control NPCs. We analyzed DNA interaction profiles of the aforementioned escapees Pctk1 and Jarid1C, as well as the silenced genes Slitrk4, MeCP2, Pcdh11x, and Sox3 (Chr X, 58.1 Mb). The latter was found as an interaction partner of active genes on the $\mathrm{X}_{\mathrm{a}}$, but is subject to $\mathrm{X}$ inactivation and appeared ignored by these and other genes on the $\mathrm{X}_{\mathrm{i}}$ chromosome. Upon depletion of Xist, the two escapees were found to contact the same (but larger) regions as well as additional ones, including the regions containing MeCP2 and Sox3. This suggests they may re-engage in specific contacts after removal of Xist (Fig. 5H). Indeed, both MeCP2 and, to a lesser degree, Sox3-as well as two other inactive genes, Pcdh11x and Slitrk4-were all found to partially regain their preference for specific genomic neighborhoods when Xist expression was lost from the inactive $\mathrm{X}$ chromosome. We noted that many of the regained interactions appeared to be similar to those found on the active $\mathrm{X}$ chromosome, and therefore asked whether depletion of Xist leads to refolding of the $\mathrm{X}_{\mathrm{i}}$ into the groundstate configuration of the active $\mathrm{X}$ chromosome. A Spearman's rank correlation analysis revealed that, indeed, when Xist is no longer expressed, the silenced genes on the $\mathrm{X}_{\mathrm{i}}$ adopt interactions more reminiscent of those seen on the $\mathrm{X}_{\mathrm{a}}$ (Fig. 5I; Supplemental Fig. S7B). This was the case for not only silenced genes, but also one of the escapees: Pctk1. On the other hand, Jarid1C showed no such changes. Taken together, these data demonstrate that depletion of Xist results in partial refolding of the $X_{i}$ chromosome into a structure more reminiscent of the $\mathrm{X}_{\mathrm{a}}$.

Changes seen in overall chromosome topology have frequently been correlated to changes in gene activity. Indeed, this led to the idea that the act of transcription might be crucial for the nuclear positioning of active genes (Sexton et al. 2007; Cook 2010). Although druginduced transcription inhibition experiments have usually failed to show appreciable changes in chromosome topology (Tumbar et al. 1999; Palstra et al. 2008; Muller et al. 2010), these experiments could not formally exclude that an initial act of gene transcription prior to drug treatment might be the force driving gene positioning. The conditional Xist knockout system used here is 
unique in that it is known to retain gene silencing, yet appears to affect gene positioning. To further exclude that genes reactivate in our system, we used an allele-specific transcription assay for 11 additional X-linked genes, nine of which are silenced and two genes escaping XCI. Only one gene, Atp $7 a$, showed slight derepression, as reported previously (Zhang et al. 2007). All others-including MeCP2, Sox3, and Slitrk4 loci-showed an identical
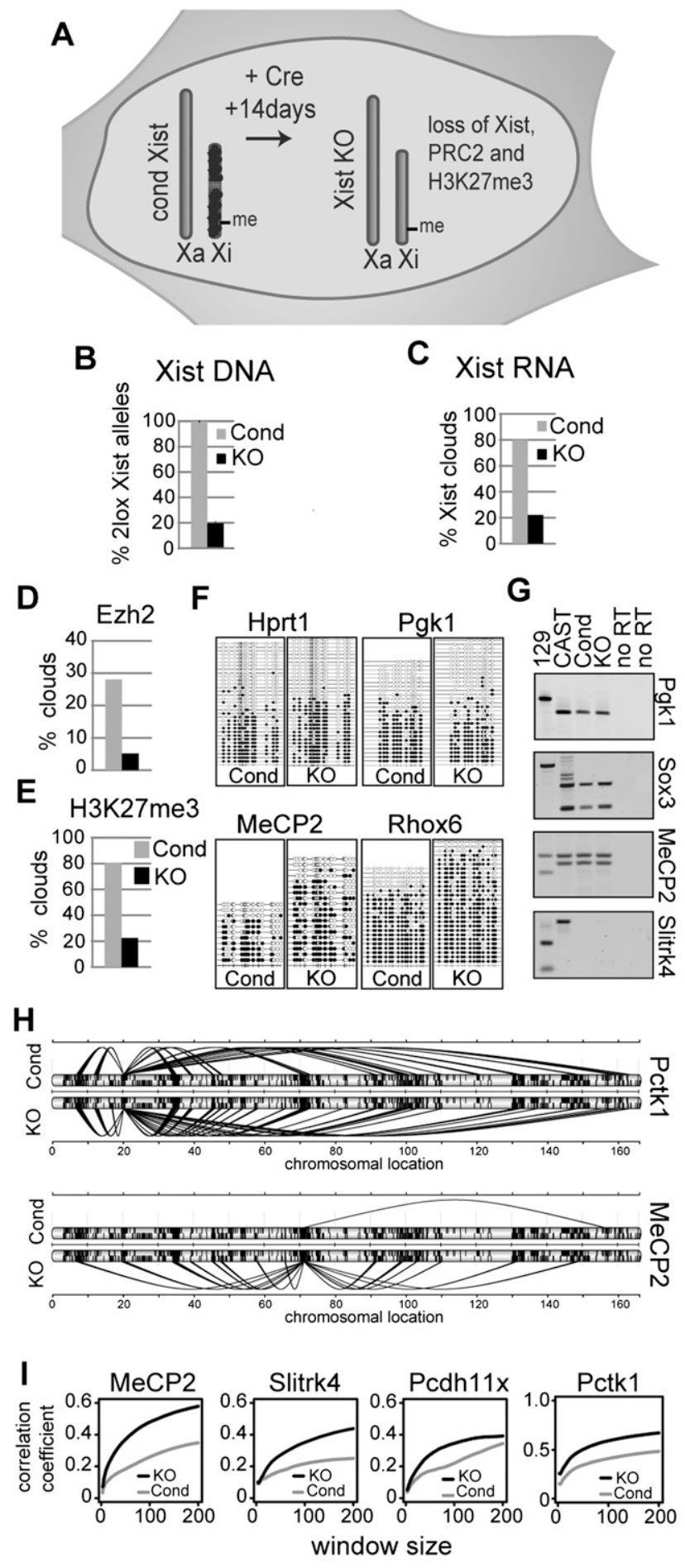

silent status on the $\mathrm{X}_{\mathrm{i}}$ with or without Xist expression (Supplemental Fig. S7C). Our data thus demonstrate that the detailed folding of the inactive $\mathrm{X}$ chromosome is very much reliant on Xist RNA, even in cells where XCI is complete. The role of Xist RNA on $\mathrm{X}_{\mathrm{i}}$ chromosome conformation may be either direct or due to the downstream recruitment of PcG and/or macro-H2A. Our data demonstrate that this function of Xist RNA is independent of gene transcription and DNA methylation, neither of which is affected after deletion of Xist.

\section{Discussion}

\section{Chromosome topology and $X$ inactivation}

The $3 \mathrm{D}$ conformation of the $\mathrm{X}$ chromosome and its position in the nucleus have been implicated in initiation and maintenance of $\mathrm{X}$ inactivation. In order to better understand the interplay between DNA topology and $\mathrm{XCI}$, detailed structural maps of both the inactive and active $\mathrm{X}$ chromosomes are needed. Here, we provide the first high-resolution interaction maps of the active and inactive X chromosomes in somatic cells that have stably established $\mathrm{X}$ inactivation. FISH experiments showed previously that escapees tend to locate at the periphery of the Xist RNA territory. In agreement with this, using 4C, providing high-resolution molecular interaction maps, we consistently found these genes to be engaged in many interchromosomal contacts. In contrast, silenced genes on the $\mathrm{X}_{\mathrm{i}}$, which are believed to reside preferentially inside the inactive Xist RNA domain, are found engaged in very few interchromosomal interactions. Importantly, we also show that escapees tend to contact each other, including the highly active Xist locus (see below), as well as the active pseudoautosomal region at the tip of the $\mathrm{X}$ chromosome. We were able to use the DNA interaction maps of escapees to identify a total of 19 genes that escape XCI in

Figure 5. The inactive $\mathrm{X}$ chromosome partially refolds to the active $\mathrm{X}$ chromosome upon conditional deletion of Xist. $(A)$ Schematic representation of the Xist knockout strategy. $(B)$ Allele-specific quantitative PCR (qPCR) result, measuring recombination efficiency. $(C)$ The quantification of the Xist RNA FISH applied on Xist ${ }^{\mathrm{KO}}$ and Xist ${ }^{\mathrm{CON}}$ NPCs. A representative example of the FISH experiment is shown in Supplemental Figure S7A. $(D, E)$ Quantification of Ezh2 and H3K27me3 clouds, respectively, identified by immunofluorescence applied on $X_{\text {Xist }}{ }^{\mathrm{KO}}$ NPCs. (F) Bisulfite sequencing result of X-linked gene promoters in both the control NPCs and Xist ${ }^{\mathrm{KO}}$ NPCs. Open circles represent nonmethylated CpGs, while methylated CpGs are represented by the filled dots. (G) Allele-specific expression analysis of four X-linked genes in control NPCs and Xist ${ }^{\mathrm{KO}}$ NPCs. Allelic transcript contribution is visualized by separating digested RT-PCR products using a RFLP-recognizing restriction enzyme on an agarose gel (see also Supplemental Fig. S7). (H) Spider plots depicting long-range interactions of Pctk $1^{\mathrm{Xi}}$ and $M e C P 2^{\mathrm{Xi}}$ identified in the control NPCs $(t o p)$ and Xist ${ }^{\mathrm{KO}}$ NPCs (bottom). (I) Spearman's rank correlation calculated comparing the 4C profiles identified in the control NPCs and Xist ${ }^{\mathrm{KO}}$ NPCs with the corresponding $X_{a}$ profile of the indicated viewpoints (see also Supplemental Fig. S7). 
NPCs (Supplemental Table S2). Previously, only a few escapees had been discovered in mice. The highest reported number of escaping genes came from a recent RNA sequencing study that identified 13 escapees in a cell line cultured from mouse embryonic kidneys (Yang et al. 2010). We confirm that nine of these escapees interact with both Jarid1c and Pctk1 in NPCs. Further allelespecific expression analysis of interacting genes led to the identification of another 10 genes that are active on the $\mathrm{X}_{\mathrm{i}}$ chromosome in NPCs (Supplemental Table S2).

Some of the escaping genes identified (Usp9x, Pctk1, and Fmr1) can be classified as tissue-specific genes, showing that tissue-specific factors may impact on the mechanisms underlying escape from XCI in mice, as was found previously in human (Prothero et al. 2009). Escapees appear to be distributed randomly along the $\mathrm{X}$ chromosome, with some in gene deserts and others in areas dense with silenced genes. This supports the idea that, in mice, the ability to escape is a gene-intrinsic property ( $\mathrm{Li}$ and Carrel 2008; Yang et al. 2010). The situation is slightly different in humans, where many more genes can escape XCI and many escapees are clustered on the short arm of the human X chromosome (Carrel and Willard 2005).

The fact that, during the XCI maintenance phase, the Xist locus interacts with escapees is interesting when considering the mechanisms of Xist RNA spreading. If diffusion through the nucleoplasm plays a role in the efficient spreading of Xist RNA across the X chromosome, it is striking that the regions spatially close to the source of Xist RNA production are not necessarily those that become silenced by Xist. It emphasizes that escapees must have powerful mechanisms to counteract Xistinduced repression. Escapees are distributed randomly across the entire $\mathrm{X}$ chromosome, implying that most will be flanked on the linear chromosome by sequences sensitive to repression by Xist. These sequences will automatically be dragged along when an escape gene loops toward the Xist locus. One could speculate that this $3 \mathrm{D}$ organization helps Xist spreading across the $\mathrm{X}$ chromosome at this stage of development, when $\mathrm{X}$ inactivation has long been established.

Our study reports for the first time that silenced genes fail to show preferred neighboring sequences in cis. This has not been reported before, as inactive regions on autosomes (Simonis et al. 2006; Lieberman-Aiden et al. 2009) and on the active X (this study) so far invariably were found to be engaged in specific contacts with other inactive regions elsewhere on their chromosomes. This novel type of organization may be a reflection of highly dynamic interactions inside the inactive $\mathrm{X}$ domain, but will also be found when a gene's spatial orientation to other chromosomal parts is relatively stable but different for each cell in the population analyzed. We speculate that the latter organization may be expected if chromosomal regions show little differences in their epigenetic landscape (see below). It will be interesting to determine whether this type of random organization of genes within the chromosome territory also occurs during other stages of differentiation and/or at other parts of the genome.
Transcription and the shape of the inactive X chromosome

Our study provides further evidence supporting the correlation between a gene's expression status and its exact position relative to other genomic regions in the nucleus (Fraser and Bickmore 2007). The outstanding question now is whether transcription and genome topology are causally related. Previous genome-wide DNA topology studies provided detailed evidence for the spatial segregation of active and inactive chromatin inside the cell nucleus (Simonis et al. 2006; Lieberman-Aiden et al. 2009). It was additionally suggested that functionally related genes preferentially come together in the nuclear space (Schoenfelder et al. 2009), although this was not immediately clear from other studies on the same genes (Simonis et al. 2006). Two extreme models may explain the link between transcription and chromosome conformation. One proposes that genes need to migrate to specific nuclear locations for their transcription (Chakalova and Fraser 2010). Another possibility is that chromosome structure and transcription are independent parameters that both follow some physical properties of chromatin. The structure of the inactive $\mathrm{X}$ chromosome, with escapees locating peripheral and silenced genes more inside the chromosome territory, is compatible with both models for nuclear organization. Our observation that escapees tend to interact with each other, though, seems to be further evidence for the idea that active genes meet at dedicated transcription sites. However, the fact that, with RNA and DNA FISH, the same percentage of interaction between pairs of escapees is measured (Supplemental Fig. S5D) suggests that the loci that are not actively transcribing meet as frequently as the transcribing loci. For example, the escaping genes Pctk1 and Fmr1, located on the $\mathrm{X}_{\mathrm{i}}$, are both active only $60 \%$ of the time (Supplemental Fig. S5E). Assuming that they independently control their bursts of transcription (Chubb et al. 2006), this means that only $\sim 36 \%$ of the cells will have both alleles transcribed at the same time on the same chromosome. Although located $40 \mathrm{Mb}$ apart, they show an interaction on the $\mathrm{X}_{\mathrm{i}}$ in $20 \%$ of the cells, as measured by DNA FISH. If this were accounted for exclusively by the actively transcribed alleles, RNA FISH would yield a much higher interaction frequency within the $36 \%$ of cells transcribing both genes. However, this is not the case, with RNA and DNA FISH measurements in cells showing the two (active) alleles do not differ significantly ( $23 \%$ vs. $20 \%$ ). The data therefore suggest that escapees colocalize in the nucleus irrespective of their transcriptional status, but perhaps due to chromatin features of these genes.

Experiments that try to address the causal relationship between nuclear positioning and transcription often manipulate the one factor and analyze its consequences for the other. Gene repositioning from the nuclear interior to the periphery via induced anchoring to the nuclear lamina is one such experiment. In one study, this was found to have no effect on a reporter's ability to activate transcription (Kumaran and Spector 2008); in another 
study, it was found to cause gene silencing (Reddy et al. 2008); and in a third study, it was found to repress some genes while not affecting others (Finlan et al. 2008). A similar lack of coherent results is apparent from studies that use transcription inhibitors to study the impact of transcription on gene positioning. Some studies reported (minor) DNA topological changes upon transcription inhibition (Mahy et al. 2002b; Branco and Pombo 2006; Naughton et al. 2010), while others, including a 4C study (Palstra et al. 2008), failed to measure an effect of transcription on DNA structure (Tumbar et al. 1999; Muller et al. 2010). Inherently, such studies may not be well suited to address this relationship though. The chemical and heat-shock treatments that block transcription also induce other types of cellular stress, making it difficult to unambiguously relate observed conformational changes to changes in transcription. Vice versa, not observing an effect does not exclude that an early act of transcription prior to (drug) treatment was responsible for setting up the 3D structure measured. Nuclear repositioning independent of changes in transcription has been observed before, but only for some individual loci and measured relative to nuclear landmarks like the chromosome territory or nuclear lamina (Morey et al. 2008; Peric-Hupkes et al. 2010). Our data provide highresolution molecular interaction maps that uncouple topological changes from transcription on a chromosome-wide scale. Following depletion of Xist, we found that genes present on the inactive $\mathrm{X}$ chromosome remained transcriptionally silent, but that the inactive $\mathrm{X}$ chromosome shows profound changes in its shape, adopting a structure reminiscent of the active X chromosome. This observation suggests that Xist-induced $\mathrm{X}$-chromosome topology does not play a role in maintenance of XCI. A recent study generated chromatin compaction profiles of the human active and inactive $\mathrm{X}$ chromosome. Only minor compaction differences between the two chromosomes were found at the 30-nm scale. However, the volume of the $\mathrm{X}_{\mathrm{a}}$, normally larger than that of the $\mathrm{X}_{\mathrm{i}}$, was demonstrated to become similar to the $\mathrm{X}_{\mathrm{i}}$ volume after transcription inhibition (Naughton et al. 2010). Our detailed DNA interaction maps of the active and inactive $\mathrm{X}$ chromosomes suggest that, although similar in size, the two $\mathrm{X}$ chromosomes in the study are likely to be folded very differently. Collectively, our data show that gene interactions and chromosome folding are at least partially independent of gene expression. A remaining possibility is that Xist depletion allows for reloading of RNA polymerase II molecules onto inactive genes that cannot complete gene transcription; such paused polymerase molecules may then be responsible for the newly gained long-range DNA interactions. Alternatively, or in parallel, factors other than polymerase may play an important role in shaping the inactive $\mathrm{X}$ chromosome.

\section{Factors shaping the inactive $X$ chromosome}

Recently, PcG proteins were found to mediate long-range intrachromosomal interactions between cognate regions tens of megabases apart in Drosophila (Bantignies et al. 2011). In addition, the PcG protein complex PRC1 has been shown to alter large-scale chromatin structures (Eskeland et al. 2010). The latter observations may be relevant for X-chromosome folding as well. A scattered presence of PcG proteins along the inactive regions of the $\mathrm{X}_{\mathrm{i}}$ chromosome may well account for the random organization of inactive chromatin that we observe inside the Barr body. After all, preferential interactions are expected to occur only when chromosomal regions differ sufficiently from each other in chromatin composition and associated factors. In addition to PcG proteins, macroH2A and, obviously, the long noncoding RNA molecule Xist itself may play a direct role in shaping the inactive $\mathrm{X}$ chromosome. The knockdown of such factors in NPCs turned out to be difficult also because their depletion, unlike that of Xist, causes genome-wide changes, rather than X-specific, epigenetic, and expression changes. Further deciphering the factors that shape the $\mathrm{X}$ therefore awaits more sophisticated strategies. Collectively, our data show that that the inactive $\mathrm{X}$ chromosome in female cells adopts a unique 3D structure that is dependent on Xist RNA and, at least partially, independent of transcription and DNA methylation.

\section{Materials and methods}

\section{Cell culture}

NPCs were generated according to Conti et al. (2005) with slight modifications. In brief, three independent 129SVJ/CAST ESC lines (Luikenhuis et al. 2001; Jonkers et al. 2008; Csankovszki et al. 1999) that remain XX upon differentiation were differentiated in N2B27 (StemCell Recourses) for 7 d, followed by the formation of neural spheres in N2B27 supplemented with EGF and FGF $(10 \mathrm{ng} / \mathrm{mL})$. Three-day-old spheres were allowed to attach to the culture dish to expand NPCs. After two passages, cells were seeded in low density and colonies were picked and analyzed for NPC identity using immunofluorescence (see below) and proper XCI. A single clone was selected from each cell line that exclusively had silenced the 129 SVI $(2 \times)$ or the CAST $(1 \times)$ $\mathrm{X}$ chromosome. Cre-mediated Xist knockout was achieved by first differentiating 129SVJ-Xist2lox/CAST ESCs (Csankovszki et al. 1999) to NPCs. NPCs showing proper XCI were transfected with pCMV-Cre-puro using Amaxa according to the manufacturer's protocol, followed by transient puromycin selection for 2 d. Xist ${ }^{\mathrm{KO}}$ NPCs were cultured an additional $12 \mathrm{~d}$, with cell numbers increasing $>10$-fold before analysis to dilute out stable $\mathrm{X}_{\mathrm{i}}$ markers.

\section{C analysis}

To distinguish between the conformation of the $\mathrm{X}_{\mathrm{a}}$ and $\mathrm{X}_{\mathrm{i}}$ in female cells, we designed an allele-specific $4 \mathrm{C}$ approach that is outlined in Figure 1A. Comparing the DNA sequence of Mus musculus domesticus and $M$. musculus castaneus employing a database of SNPs (Frazer et al. 2007) or after PCR amplification and sequencing, we confirmed/identified restriction fragment length polymorphisms (RFLPs). Based on identified RFLPs, we were able to design an allele-specific 4C strategy when applied on SVI129/CAST cells. The initial steps of the 4C procedure, as published before (Simonis et al. 2006), remain unchanged. Cells are cross-linked using formaldehyde, after which chromatin is 
digested and subsequently ligated under diluted conditions. After reversal of the cross-links, the DNA is purified and ready for the second restriction enzyme treatment. In order to design an allele-specific 4C procedure, the viewpoint fragment is chosen such that a RFLP is located in between the primers used in the PCR amplification. As a consequence, only the allele that is not digested by the second restriction enzyme can contribute to the 4C PCR product and is analyzed by either dedicated microarray or high-throughput sequencing. An example of the allele-specific formation of 4C PCR product is shown in Figure 1B, where Jarid1C amplifies only from the SVJ129 template with high efficiency. As a control, the Hbb-bl primers, which were not designed around a RFLP, were able to amplify similar amounts of PCR product from both templates. An alternative strategy that allows the use of a "RFLP-recognizing" restriction enzyme that is sensitive to CpG methylation is depicted in Supplemental Figure S1. Primer design and PCR product analysis were adapted to include the use of Illumina sequencing (see also Supplemental Fig. S1 for detailed information). SNPs and primers used in the $4 \mathrm{C}$ analysis are listed in Supplemental Table S3. All data obtained for the $X_{i}$ and some for the $X_{a}(M e C P 2)$ were verified in independent NPC clones, giving highly similar interaction profiles (data not shown). RFLPs in Pcdh11x allowed independent $4 \mathrm{C}$ analysis of both the $\mathrm{X}_{\mathrm{i}}^{129}$ and $\mathrm{X}_{\mathrm{i}}^{\mathrm{CAST}}$ chromosomes, which demonstrated that folding was highly similar between the genetically distinct $\mathrm{X}$ chromosomes (data not shown).

\section{Data analysis}

To identify interacting regions, we set up a standardized 4C-seq data analysis work flow. The initial step in the 4C-seq analysis is the alignment of the sequencing reads to a reduced genome of sequences that flank HindIII sites (fragment ends) using custom PERL scripts. Due to their ambiguous nature in reporting contacts, repetitive fragment ends were excluded from subsequent analysis. The reduced genome was based on mouse $\mathrm{mm} 9$. The data have been deposited in the Gene Expression Omnibus (GEO) under accession number GSE29509. The proportional distribution of reads identified in the different experiments can be found in Supplemental Figure S4A.

All statistical analysis was performed using the $\mathrm{R}$ programming language (http://www.R-project.org). To avoid possible PCR artifacts, we transformed the data to unique coverage (more than one read per fragment end is set to 1). Because the coverage declines as a function of the distance from the viewpoint (i.e., high coverage close to the viewpoint and low at larger distances), we normalized the coverage for the background coverage. To this end, we calculated $Z$-scores for a given window of fragment ends $i$, of size $w$, based on the relative unique coverage in the background window $W\left(\mathrm{p}_{\mathrm{W}, \mathrm{I}}=\operatorname{cov}_{\mathrm{I}} / W\right.$, where $\operatorname{cov}_{\mathrm{I}}$ is the number of unique fragment ends covered in window $I)$. We choose $I$ such that $I \gg i$ and $i$ runs from $[w / 2]$ until $N-[w / 2]$, where $N$ is the number of fragment ends on the chromosome. Window $i$ spans $i-[w / 2]$ until $i+[w / 2]$ for odd values of $w$ and $(i-w / 2)+1$ until $i+w / 2$ for even values of $w$. In general, $I=i$, except for values where $I<W$ and $I>N-W$, where $I=W$ or $I=N-W$, respectively. We calculated estimators for the mean and standard deviations $(\mu$ and $\sigma)$ following the binomial distribution for every window $i$ given a window size $w$ :

$$
\mu_{W, i}=W \cdot p_{W}, \sigma_{W, i}=W \cdot p_{W, i} \cdot\left(1-p_{W, i}\right)
$$

We use the relative unique coverage in window $w\left(\mathrm{p}_{\mathrm{w}}\right)$ to calculate the $Z$-score:

$$
z_{W, i}=\frac{p_{w, i}-\mu_{W, i}}{\sigma_{W, i}}
$$

To identify regions of nonrandom $4 \mathrm{C}$ signals (i.e., contacted regions) we used the false discovery rate (FDR). To this end, we randomly permuted the data set 100 times and determined the threshold $Z$-score at which the FDR was 0.01. For the trans interactions, an FDR threshold of 0.01 was determined based on 100 random permutations of the data for every chromosome. A window size of 500 was used; windows that exceeded the threshold were scored as trans interactions.

The domainogram analysis was performed analogous to de Wit et al. (2008), but using a matrix of probability scores based on the matrix of $Z$-scores $\left(z_{W}, w=2,3, \ldots 200\right)$. Probability scores were calculated based on the normal distribution. A $\log _{10}$ transformation of the probability score is used in the visualization.

\section{Correlation analysis}

Correlation analysis between different 4C experiments was performed by calculating the Spearman's coefficient of rank correlation $(\rho)$ between the set of $Z$-scores $Z_{W}$ (collection of all $\left.Z_{W, i}\right)$, between two $4 \mathrm{C}$ experiments over a range of values for w. Supplemental Figure S7A depicts a visual example.

\section{Genomic annotation}

Gene density scores were calculated based on the RefSeq annotation downloaded from the University of California at Santa Cruz (UCSC) Table Browser (Karolchik et al. 2004). Repeat density analysis was based on LINE and SINE annotation from the Ensembl core version 59 (Flicek et al. 2011). Neural progenitor expression data from Mikkelsen et al. (2007) was used and can be downloaded under GEO accession number GSE8024. Raw CEL files were normalized using RMA in the Bioconductor affy package (Bolstad et al. 2003), and were subsequently combined to one expression value. Probe locations were downloaded from the UCSC Table Browser, and redundant probe locations were removed from the data.

\section{Immunofluorescence}

ESCs and NPCs cultured on coverslips were fixed in PBS containing $3 \%$ paraformaldehyde for $10 \mathrm{~min}$ and permeablized in $\mathrm{PBS} / 0.4 \%$ Triton $\mathrm{X}-100$ for $5 \mathrm{~min}$ on ice. Blocking and antibody hybridizations were performed for $2 \mathrm{~h}$ at room temperature using $\mathrm{PBS} / 10 \%$ fetal calf serum $/ 0.05 \%$ Tween-20. Antibodies used are as follows: for Oct4, ab19857 (Abcam); for Nestin, ab6142 (Abcam); for Gfap, ab4648 (Abcam); for Tubulin, ab7751 (Abcam); for EZH2, 612666 (BD Biosciences); for H3K27me3, ab6002 (Abcam); for donkey anti-mouse IgG A594, 715-515-150 (Jackson); and for goat anti-rabbit IgG FITC, 111095-003 (Jackson). DAPI was used for DNA counterstaining. Images were collected using a Leica DM6000 B microscope equipped with a Leica DFC360 FX camera and Leica application suite 2.2.1 software.

\section{RNA FISH and DNA FISH}

RNA FISH and DNA FISH experiments were performed as described previously (Chaumeil et al. 2006), except cells were fixed before permeabilization. The following BAC clones were used as probes in the analysis: for Pctk1, RP23-362P12; for Fmr, RP24-183G11; for Mecp2, RP23-77L16; for ChrX: 87.2 Mb, 
RP23-25P21; for Xist, CT7-399K20; for Taf1/Ogt, RP23-268G11; for Chm, RP23-118M16; for Pcdh11x, RP23-20G23; and for Jarid1C, RP24-148H21. For the generation of probes, $300 \mathrm{ng}$ of Sau3AI-digested BAC DNA was fluorescently labeled with Cy5 dUTP (NEL 579001 EA, Perkin Elmer), Spectrum Orange dUTP (02N33-050, Enzo Life Sciences), or spectrum green dUTP (02N32-050, Enzo Life Sciences) using the BioPrime Array CGH genomic labeling system (Invitrogen) following the manufacturer's protocol. Specificity of the labeled probes was confirmed on metaphase spreads from mouse ESCs. 3D images were collected using a Leica DM6000 B microscope equipped with a $100 \times$ objective and Leica DFC360 FX camera, taking $z$-steps of $0.2 \mu \mathrm{m}$. Leica application suite 2.2.1 software was used for both image collection and deconvolution. 3D distance measurements were taken of 100 nuclei per data point using ImageJ software. Xist RNA costaining allowed us to measure distances of both the $\mathrm{X}_{\mathrm{a}}$ and $\mathrm{X}_{\mathrm{i}}$ in the same nucleus. Measurements were taken only if signals from both chromosomes could be identified.

\section{Allele-specific expression analysis}

Allele-specific expression analysis based on RFLPs between $X^{129}$ and $\mathrm{X}^{\text {CAST }}$ was performed as described before (Huynh and Lee 2003). In brief, RNA was isolated using TRIzol following the manufacturer's instructions. RNA was treated with DNase and converted into cDNA using random primers (Promega). PCR primers spanning a RFLP were used for the detection of gene transcripts. PCR products were digested with the appropriate restriction enzyme and separated by agarose gel electrophoreses. Images were captured using a Typhoon 9410 scanner (GE Healthcare) and analyzed using ImageQuant software. SNPs and primers used in this analysis are listed in Supplemental Table S3.

\section{Quantitative PCR ( $q P C R)$}

qPCR analysis was performed using MyIQ PCR machines and MyIQ software (Bio-Rad) using standard SYBR Green incorporation to detect PCR products. The primers used are listed in Supplemental Table S3.

\section{Bisulfite sequencing}

Bisulfite conversion was performed using the EZ DNA Methylation-Direct kit (Zymo Research). Primers were designed using MethPrimer (Li and Dahiya 2002) and are listed in Supplemental Table S3. Correct PCR products were isolated from agarose gel, cloned into pGEMT-easy, and transformed. Forty-eight colonies were picked and sequenced per condition. Sequencing data were analyzed using QUMA analysis tool (http://quma.cdb.riken.jp), including only sequences showing $>90 \%$ identity and C-T conversion.

\section{Acknowledgments}

We thank Eric Engelen for technical assistance and Patrick Wijchers for critical reading of the manuscript. This work was financially supported by grants from the Dutch Scientific Organization (NWO) to E.d.W. (700.10.402, "Veni") and W.d.L. (91204082 and 935170621), InteGeR FP7 Marie Curie ITN (PITN-GA-2007-214902), and a European Research Council Starting Grant (209700, “4C") to W.d.L.

\section{References}

Bantignies F, Roure V, Comet I, Leblanc B, Schuettengruber B, Bonnet J, Tixier V, Mas A, Cavalli G. 2011. Polycomb- dependent regulatory contacts between distant Hox loci in Drosophila. Cell 144: 214-226.

Barakat TS, Gribnau J. 2010. X chromosome inactivation and embryonic stem cells. Adv Exp Med Biol 695: 132-154.

Bolstad BM, Irizarry RA, Astrand M, Speed TP. 2003. A comparison of normalization methods for high density oligonucleotide array data based on variance and bias. Bioinformatics 19: 185-193.

Bolzer A, Kreth G, Solovei I, Koehler D, Saracoglu K, Fauth C, Muller S, Eils R, Cremer C, Speicher MR, et al. 2005. Threedimensional maps of all chromosomes in human male fibroblast nuclei and prometaphase rosettes. PLOS Biol 3: e157. doi: 10.1371/journal.pbio.0030157.

Branco MR, Pombo A. 2006. Intermingling of chromosome territories in interphase suggests role in translocations and transcription-dependent associations. PLoS Biol 4: e138. doi: 1371/journal.pbio.0040138.

Carrel L, Willard HF. 2005. X-inactivation profile reveals extensive variability in $\mathrm{X}$-linked gene expression in females. Nature 434: 400-404.

Chakalova L, Fraser P. 2010. Organization of transcription. Cold Spring Harb Perspect Biol 2: a000729. doi: 10.1101/cshperspect. 000729.

Chaumeil J, Le Baccon P, Wutz A, Heard E. 2006. A novel role for Xist RNA in the formation of a repressive nuclear compartment into which genes are recruited when silenced. Genes Dev 20: 2223-2237.

Chubb JR, Trcek T, Shenoy SM, Singer RH. 2006. Transcriptional pulsing of a developmental gene. Curr Biol 16: 10181025.

Clemson CM, Hall LL, Byron M, McNeil J, Lawrence JB. 2006. The $\mathrm{X}$ chromosome is organized into a gene-rich outer rim and an internal core containing silenced nongenic sequences. Proc Natl Acad Sci 103: 7688-7693.

Conti L, Pollard SM, Gorba T, Reitano E, Toselli M, Biella G, Sun Y, Sanzone S, Ying QL, Cattaneo E, et al. 2005. Nicheindependent symmetrical self-renewal of a mammalian tissue stem cell. PLoS Biol 3: e283. doi: 10.1371/journal.pbio. 0030283.

Cook PR. 2010. A model for all genomes: the role of transcription factories. J Mol Biol 395: 1-10.

Croft JA, Bridger JM, Boyle S, Perry P, Teague P, Bickmore WA. 1999. Differences in the localization and morphology of chromosomes in the human nucleus. J Cell Biol 145: 11191131 .

Csankovszki G, Panning B, Bates B, Pehrson JR, Jaenisch R. 1999. Conditional deletion of Xist disrupts histone macroH2A localization but not maintenance of $\mathrm{X}$ inactivation. Nat Genet 22: 323-324.

Dekker J, Rippe K, Dekker M, Kleckner N. 2002. Capturing chromosome conformation. Science 295: 1306-1311.

de Laat W, Grosveld F. 2007. Inter-chromosomal gene regulation in the mammalian cell nucleus. Curr Opin Genet Dev 17: 456-464.

de Wit E, Braunschweig U, Greil F, Bussemaker HJ, van Steensel B. 2008. Global chromatin domain organization of the Drosophila genome. PLoS Genet 4: e1000045. doi: 10.1371/ journal.pgen. 1000045.

Dietzel S, Schiebel K, Little G, Edelmann P, Rappold GA, Eils R, Cremer C, Cremer T. 1999. The 3D positioning of ANT2 and ANT3 genes within female X chromosome territories correlates with gene activity. Exp Cell Res 252: 363-375.

Disteche CM. 1995. Escape from X inactivation in human and mouse. Trends Genet 11: 17-22.

Dostie J, Richmond TA, Arnaout RA, Selzer RR, Lee WL, Honan TA, Rubio ED, Krumm A, Lamb J, Nusbaum C, et al. 2006. 
Chromosome conformation capture carbon copy (5C): a massively parallel solution for mapping interactions between genomic elements. Genome Res 16: 1299-1309.

Drissen R, Palstra RJ, Gillemans N, Splinter E, Grosveld F, Philipsen S, de Laat W. 2004. The active spatial organization of the $\beta$-globin locus requires the transcription factor EKLF. Genes Dev 18: 2485-2490.

Duan Z, Andronescu M, Schutz K, McIlwain S, Kim YJ, Lee C, Shendure J, Fields S, Blau CA, Noble WS. 2010. A threedimensional model of the yeast genome. Nature 465: 363 367.

Eskeland R, Leeb M, Grimes GR, Kress C, Boyle S, Sproul D, Gilbert N, Fan Y, Skoultchi AI, Wutz A, et al. 2010. Ring1B compacts chromatin structure and represses gene expression independent of histone ubiquitination. Mol Cell 38: 452-464.

Finlan LE, Sproul D, Thomson I, Boyle S, Kerr E, Perry P, Ylstra B, Chubb JR, Bickmore WA. 2008. Recruitment to the nuclear periphery can alter expression of genes in human cells. PLoS Genet 4: e1000039. doi: 10.1371/journal.pgen. 10000039 .

Flicek P, Amode MR, Barrell D, Beal K, Brent S, Chen Y, Clapham P, Coates G, Fairley S, Fitzgerald S. 2011. Ensembl 2011. Nucleic Acids Res 39: D800-D806. doi: 10.1093/nar/ gkq1064.

Fraser P, Bickmore W. 2007. Nuclear organization of the genome and the potential for gene regulation. Nature 447: 413-417.

Frazer KA, Eskin E, Kang HM, Bogue MA, Hinds DA, Beilharz EJ, Gupta RV, Montgomery J, Morenzoni MM, Nilsen GB, et al. 2007. A sequence-based variation map of 8.27 million SNPs in inbred mouse strains. Nature 448: 1050-1053.

Grimaud C, Becker PB. 2009. The dosage compensation complex shapes the conformation of the $\mathrm{X}$ chromosome in Drosophila. Genes Dev 23: 2490-2495.

Huynh KD, Lee JT. 2003. Inheritance of a pre-inactivated paternal X chromosome in early mouse embryos. Nature 426: $857-862$.

Jonkers I, Monkhorst K, Rentmeester E, Grootegoed JA, Grosveld F, Gribnau J. 2008. Xist RNA is confined to the nuclear territory of the silenced $\mathrm{X}$ chromosome throughout the cell cycle. Mol Cell Biol 28: 5583-5594.

Kagey MH, Newman JJ, Bilodeau S, Zhan Y, Orlando DA, van Berkum NL, Ebmeier CC, Goossens J, Rahl PB, Levine SS, et al. 2010. Mediator and cohesin connect gene expression and chromatin architecture. Nature 467: 430-435.

Karolchik D, Hinrichs AS, Furey TS, Roskin KM, Sugnet CW, Haussler D, Kent WJ. 2004. The UCSC Table Browser data retrieval tool. Nucleic Acids Res 32: D493-D496. doi: 10.1093/nar/gkh103.

Kohlmaier A, Savarese F, Lachner M, Martens J, Jenuwein T, Wutz A. 2004. A chromosomal memory triggered by Xist regulates histone methylation in $\mathrm{X}$ inactivation. PLoS Biol 2: e171. doi: 10.1371/journal.pbio.002071.

Kumaran RI, Spector DL. 2008. A genetic locus targeted to the nuclear periphery in living cells maintains its transcriptional competence. J Cell Biol 180: 51-65.

Li N, Carrel L. 2008. Escape from X chromosome inactivation is an intrinsic property of the Jarid1c locus. Proc Natl Acad Sci 105: 17055-17060.

Li LC, Dahiya R. 2002. MethPrimer: designing primers for methylation PCRs. Bioinformatics 18: 1427-1431.

Lieberman-Aiden E, van Berkum NL, Williams L, Imakaev M, Ragoczy T, Telling A, Amit I, Lajoie BR, Sabo PJ, Dorschner $\mathrm{MO}$, et al. 2009. Comprehensive mapping of long-range interactions reveals folding principles of the human genome. Science 326: 289-293.
Luikenhuis S, Wutz A, Jaenisch R. 2001. Antisense transcription through the Xist locus mediates Tsix function in embryonic stem cells. Mol Cell Biol 21: 8512-8520.

Mahy NL, Perry PE, Bickmore WA. 2002a. Gene density and transcription influence the localization of chromatin outside of chromosome territories detectable by FISH. I Cell Biol 159: 753-763.

Mahy NL, Perry PE, Gilchrist S, Baldock RA, Bickmore WA. 2002b. Spatial organization of active and inactive genes and noncoding DNA within chromosome territories. J Cell Biol 157: 579-589.

Mikkelsen TS, Ku M, Jaffe DB, Issac B, Lieberman E, Giannoukos G, Alvarez P, Brockman W, Kim TK, Koche RP, et al. 2007. Genome-wide maps of chromatin state in pluripotent and lineage-committed cells. Nature 448: 553-560.

Misteli T. 2001. The concept of self-organization in cellular architecture. J Cell Biol 155: 181-185.

Morey C, Da Silva NR, Kmita M, Duboule D, Bickmore WA. 2008. Ectopic nuclear reorganisation driven by a Hoxb 1 transgene transposed into Hoxd. J Cell Sci 121: 571-577.

Muller I, Boyle S, Singer RH, Bickmore WA, Chubb JR. 2010. Stable morphology, but dynamic internal reorganisation, of interphase human chromosomes in living cells. PLOS ONE 5: e11560. doi: 10.1371/journal.pone.0011560.

Naughton C, Sproul D, Hamilton C, Gilbert N. 2010. Analysis of active and inactive $\mathrm{X}$ chromosome architecture reveals the independent organization of $30 \mathrm{~nm}$ and large-scale chromatin structures. Mol Cell 40: 397-409.

Osborne CS, Chakalova L, Brown KE, Carter D, Horton A, Debrand E, Goyenechea B, Mitchell JA, Lopes S, Reik W, et al. 2004. Active genes dynamically colocalize to shared sites of ongoing transcription. Nat Genet 36: 1065-1071.

Palstra, R.J., Simonis, M., Klous, P., Brasset, E., Eijkelkamp, B., and de Laat, W. 2008. Maintenance of long-range DNA interactions after inhibition of ongoing RNA polymerase II transcription. PLoS One 3: e1661. doi: 10.1371/journal.pone.0001661.

Papantonis A, Larkin JD, Wada Y, Ohta Y, Ihara S, Kodama T, Cook PR. 2010. Active RNA polymerases: mobile or immobile molecular machines? PLOS Biol 8: e1000419. doi: 10.1371/journal.pbio.1000419.

Peric-Hupkes D, Meuleman W, Pagie L, Bruggeman SW, Solovei I, Brugman W, Graf S, Flicek P, Kerkhoven RM, van Lohuizen M, et al. 2010. Molecular maps of the reorganization of genome-nuclear lamina interactions during differentiation. Mol Cell 38: 603-613.

Prothero KE, Stahl JM, Carrel L. 2009. Dosage compensation and gene expression on the mammalian X chromosome: one plus one does not always equal two. Chromosome Res 17: 637-648.

Pullirsch D, Hartel R, Kishimoto H, Leeb M, Steiner G, Wutz A. 2010. The Trithorax group protein Ash21 and Saf-A are recruited to the inactive $\mathrm{X}$ chromosome at the onset of stable X inactivation. Development 137: 935-943.

Reddy KL, Zullo JM, Bertolino E, Singh H. 2008. Transcriptional repression mediated by repositioning of genes to the nuclear lamina. Nature 452: 243-247.

Rodley CD, Bertels F, Jones B, O'Sullivan JM. 2009. Global identification of yeast chromosome interactions using Genome conformation capture. Fungal Genet Biol 46: 879-886.

Schoenfelder S, Sexton T, Chakalova L, Cope NF, Horton A, Andrews S, Kurukuti S, Mitchell JA, Umlauf D, Dimitrova DS, et al. 2009. Preferential associations between co-regulated genes reveal a transcriptional interactome in erythroid cells. Nat Genet 42: 53-61.

Senner CE, Brockdorff N. 2009. Xist gene regulation at the onset of X inactivation. Curr Opin Genet Dev 19: 122-126. 
Sexton T, Umlauf D, Kurukuti S, Fraser P. 2007. The role of transcription factories in large-scale structure and dynamics of interphase chromatin. Semin Cell Dev Biol 18: 691-697.

Simonis M, Klous P, Splinter E, Moshkin Y, Willemsen R, de Wit E, van Steensel B, de Laat W. 2006. Nuclear organization of active and inactive chromatin domains uncovered by chromosome conformation capture-on-chip (4C). Nat Genet 38: $1348-1354$.

Tumbar T, Sudlow G, Belmont AS. 1999. Large-scale chromatin unfolding and remodeling induced by VP16 acidic activation domain. J Cell Biol 145: 1341-1354.

Wutz A, Jaenisch R. 2000. A shift from reversible to irreversible $\mathrm{X}$ inactivation is triggered during ES cell differentiation. Mol Cell 5: 695-705.

Wutz A, Rasmussen TP, Jaenisch R. 2002. Chromosomal silencing and localization are mediated by different domains of Xist RNA. Nat Genet 30: 167-174.

Yang F, Babak T, Shendure J, Disteche CM. 2010. Global survey of escape from $\mathrm{X}$ inactivation by RNA-sequencing in mouse. Genome Res 20: 614-622.

Zhang LF, Huynh KD, Lee JT. 2007. Perinucleolar targeting of the inactive $\mathrm{X}$ during $\mathrm{S}$ phase: evidence for a role in the maintenance of silencing. Cell 129: 693-706. 


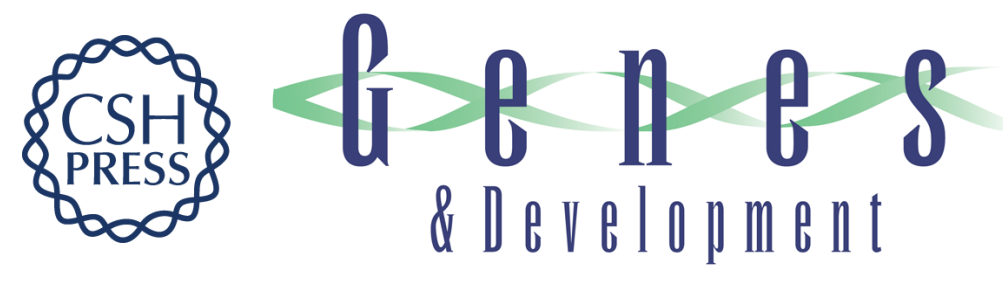

\section{The inactive $X$ chromosome adopts a unique three-dimensional conformation that is dependent on Xist RNA}

Erik Splinter, Elzo de Wit, Elphège P. Nora, et al.

Genes Dev. 2011, 25: originally published online June 20, 2011

Access the most recent version at doi:10.1101/gad.633311

\section{Supplemental http://genesdev.cshlp.org/content/suppl/2011/06/21/gad.633311.DC1 Material}

References This article cites 62 articles, 20 of which can be accessed free at: http://genesdev.cshlp.org/content/25/13/1371.full.html\#ref-list-1

\section{License}

Email Alerting

Receive free email alerts when new articles cite this article - sign up in the box at the top Service

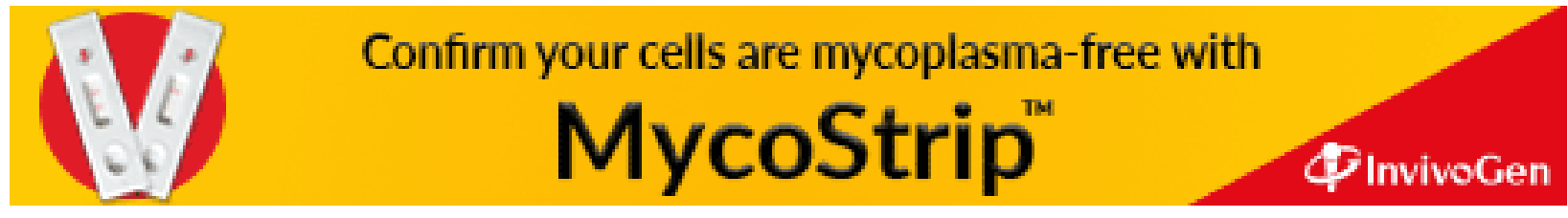

